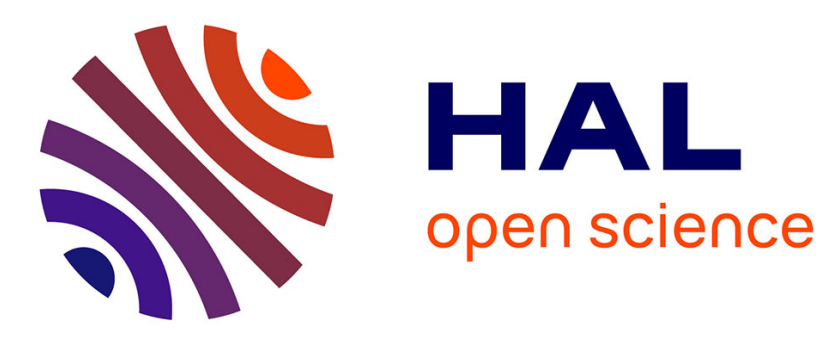

\title{
Stock Return Predictability: Evaluation based on prediction intervals
}

\author{
Amélie Charles, Olivier Darné, Jae H. Kim
}

\section{To cite this version:}

Amélie Charles, Olivier Darné, Jae H. Kim. Stock Return Predictability: Evaluation based on prediction intervals. 2016. hal-01295037

\section{HAL Id: hal-01295037 \\ https://hal.science/hal-01295037}

Preprint submitted on 30 Mar 2016

HAL is a multi-disciplinary open access archive for the deposit and dissemination of scientific research documents, whether they are published or not. The documents may come from teaching and research institutions in France or abroad, or from public or private research centers.
L'archive ouverte pluridisciplinaire HAL, est destinée au dépôt et à la diffusion de documents scientifiques de niveau recherche, publiés ou non, émanant des établissements d'enseignement et de recherche français ou étrangers, des laboratoires publics ou privés. 
EA 4272

\title{
Stock Return Predictability: Evaluation based on prediction intervals
}

\author{
Amélie Charles* \\ Olivier Darné** \\ Jae H. Kim***
}

2016/04

$\left(^{*}\right)$ Audencia Business School, Nantes

$\left({ }^{* *}\right)$ LEMNA - Université de Nantes

$\left.{ }^{(* *}\right)$ Department of Finance - La Trobe Business School - La Trobe University - Australia

Laboratoire d'Economie et de Management Nantes-Atlantique Université de Nantes

Chemin de la Censive du Tertre - BP 52231

44322 Nantes cedex 3 - France

www.univ-nantes.fr/iemn-iae/recherche

Tél. +33 (0)2 40141717 - Fax +33 (0)2 40141749 


\title{
Stock Return Predictability: Evaluation based on Prediction Intervals
}

\author{
Amélie CHARLES* \\ Audencia Nantes, School of Management \\ Olivier DARNÉ ${ }^{\dagger \ddagger}$ \\ LEMNA, University of Nantes \\ Jae H. KIM ${ }^{\S}$ \\ Department of Economics and Finance, La Trobe University
}

${ }^{*}$ Audencia Nantes, School of Management, 8 route de la Jonelire, 44312 Nantes, France. Email: acharles@audencia.com.

${ }^{\dagger}$ LEMNA, University of Nantes, IEMN-IAE, Chemin de la Censive du Tertre, BP 52231, 44322 Nantes, France. Email: olivier.darne@univ-nantes.fr.

${ }^{\ddagger}$ Olivier Darné gratefully acknowledge financial support from the Chaire Finance of the University of Nantes Research Foundation.

$\S$ Corresponding Author: J.Kim@latrobe.edu.au; All computations are conducted using the VAR.etp package (Kim, 2015) written in R ( $\mathrm{R}$ Core team, 2015). The $\mathrm{R}$ codes used in this paper are available from the authors on request. A part of this paper was written while the third author was visiting LEMNA, University of Nantes, France, who gratefully acknowledges the financial support and hospitality. 


\begin{abstract}
This paper evaluates the predictability of monthly stock return using out-of-sample (multi-step ahead and dynamic) prediction intervals. Past studies have exclusively used point forecasts, which are of limited value since they carry no information about the intrinsic predictive uncertainty associated. We compare empirical performances of alternative prediction intervals for stock return generated from a naive model, univariate autoregressive model, and multivariate model (predictive regression and VAR), using the U.S. data from 1926. For evaluation free from data snooping bias, we adopt moving sub-sample windows of different lengths. It is found that the naive model often provides the most informative prediction intervals, outperforming those generated from the univariate model and multivariate models incorporating a range of economic and financial predictors. This strongly suggests that the U.S. stock market has been informationally efficient in the weakform as well as in the semi-strong form, subject to the information set considered in this study.
\end{abstract}

Keywords: Autoregressive Model, Bootstrapping, Financial Ratios, Forecasting, Interval Score, Market Efficiency

JEL Classification: G12, G14. 


\section{Introduction}

Stock return predictability has been an issue of profound importance in empirical finance. It has strong implications to investment decisions and strategies, as well as to the fundamental concepts such as market efficiency. The empirical literature is extensive, ranging from the seminal works of Campbell and Shiller (1988) and Fama and French (1988) to the notable recent contributions such as Welch and Goyal (2008) and Neely et al. (2014). While a number of recent studies evaluate outof-sample predictability of stock return, they rely exclusively on point forecasting (e.g., Welch and Goyal, 2008; Campbell and Thompson, 2008; Lettau and Van Nieuwerburgh, 2008; Rapach et al., 2010; Westerlund and Narayan, 2012). A point forecast is a single number as an estimate of the unknown future value. Although it may represent the most likely outcome from a predictive distribution, it carries no information about the degree of intrinsic uncertainty or variability associated. For this reason, one may justifiably argue that comparison of point forecasts only is of limited value for assessing predictability. As Chatfield (1993) and Christoffersen (1998) argue, interval forecast (or prediction interval) is of a higher value to decision-makers, allowing for a more complete and informative evaluation of predictability (see also De Gooijer and Hyndman, 2006; Pan and Politis, 2016). This is particularly so for stock returns which show a high degree of volatility over time. This paper contributes to the extant literature on stock return predictability by evaluating out-of-sample prediction intervals.

A prediction interval consists of an upper and a lower limit between which the future value is expected to lie with a prescribed probability (Chatfield, 1993). As an estimate of possible future scenario, it is substantially more informative than a single value. It shows the possible direction of future value, also giving a clear indication about the extent of uncertainty associated. A tight interval is informative to decision-makers, since they can be highly confident about the future outcome, given the prescribed probability content. In contrast, a wide one carries little information about the future outcome, indicating a high degree of uncertainty. Prediction intervals can be generated from popular linear forecasting models available in many econometric packages, including the predictive regression models for stock return (see, for example, Welch and Goyal, 2008; Amihud et. al, 2004; and Kim, 2014). Conventionally, a prediction interval is constructed based on an asymptotic (normal) approximation to the predictive distribution, 
ignoring estimation uncertainty. An alternative is the bootstrap method, which provides a non-parametric approximation to the predictive distribution based on data resampling (see Pan and Politis, 2016). It is capable of generating prediction intervals which take full account of estimation uncertainty and without resorting to the normality assumption.

In this paper, we consider prediction intervals based on a range of linear models, which are widely used in practice to predict stock return at the monthly frequency. For the univariate case, an autoregressive (AR) model is used. For the multivariate case, the predictive regression and vector autoregressive (VAR) model are used. The AR model is constructed with an assumption that the stock return depends on its own past only. The $\operatorname{AR}(0)$ model represents a naive model where the stock return has no dependency on its own past. The predictive regression specifies that the stock return depends on the past of a predictor such as financial and macroeconomic variables (e.g., Welch and Goyal, 2008; Campbell and Thomson, 2008; Lettau and Van Nieuwerburgh, 2008; Rapach et al., 2010; Westerlund and Narayan, 2012). The VAR model represents a general linear model which specifies the stock return as a function of its own past and the past of its predictor. For the predictive regression and VAR models, we employ bias-corrected parameter estimation to construct prediction intervals free from small sample estimation bias (see Stambaugh, 1999). We mainly consider prediction intervals generated based on the conventional normal approximation to the predictive distribution, but a bootstrap alternative is also considered. As a means of comparison, we use the coverage rate and interval score (Gneiting and Raftery, 2007; p.370). While the former is a dichotomous measure as to whether prediction interval covers the true value or not, the latter is a quality-based measure which captures both accuracy and variability of prediction.

To the best of our knowledge, this paper is the first study examining the stock return predictability using prediction intervals. As already mentioned, the previous studies exclusively evaluate point forecasts, often accompanied by predictive ability tests. Our study represents the emphasis of estimation over testing, which more directly address the effect size of prediction. In light of the recent warnings and concerns expressed by the American Statistical Association (Wasserstein and Lazar, 2016) for the scientific findings entirely based on the p-value approach to statistical significance, our study is unique and novel in the literature of stock return predictability. The main question of our study is whether the informative 
quality of prediction interval improves as additional information is incorporated into the model. If the $\mathrm{AR}(0)$ model is found to generate the prediction interval of the highest quality, this is an indication that the additional information such as the past values of stock return or those of the predictors adds little value to the predictability of stock return. If a multivariate model with a particular predictor appears to be the clear winner, it serves as evidence that the predictor has a strong predictive power for stock return. We use the monthly data set compiled by Welch and Goyal (2008) for the U.S. stock market, which contains stock return and a range of potential predictors from 1926 to 2014, including the dividend yield, dividend-payout ratio, book-to-market ratio, price-earnings ratio, inflation rate, and risk-free rate. We extent these predictors by considering two macroeconomic variables (the industrial production growth and the output gap), because they are found to be informative about expected business conditions (Cooper and Priestley, 2009; Schrimpf, 2010); and the index of economic policy uncertainty proposed by Baker et al. (2015) because the economic uncertainty is found to affect financial markets (see, e.g., Bekaert et al., 2009; Brogaard and Detzel, 2015; Bali and Zhou, 2016). Evaluation of alternative out-of-sample prediction intervals is conducted in a purely empirical setting by calculating the mean coverage rate and interval score using the realized future values. For evaluation free from data snooping bias and possible structural changes, we apply moving sub-sample windows with a set of different window lengths.

The main finding of the paper is that the prediction intervals from the naive $\mathrm{AR}(0)$ model often outperform those generated from the models with additional information content. The univariate and multivariate models show little evidence of generating more accurate and informative prediction intervals than the $\operatorname{AR}(0)$ model. This suggests that the U.S. stock return has been unpredictable and that the market has been efficient in the weak and semi-strong forms, subject to the information content considered on this study. The next section presents a brief review of the relevant literature. Section 3 presents the methodologies, and Section 4 presents the data and computational details with illustrative examples. The empirical results are discussed in Section 5, and the conclusion is drawn in Section 6. 


\section{A Brief Literature Review}

Given that the empirical literature of stock return predictability is broad and expansive, we provide a brief review of past studies focusing on those that evaluate out-of-sample predictability. We also point out the limitations of the past studies, and highlight the contribution of our study in the context of extant literature.

Whether stock return is predictable from an economic fundamental has been an issue of much interest and contention in empirical finance. The literature on return predictability has brought more questions than answers. In the first models, such as Samuelson $(1965,1969)$ and Merton (1969), excess returns were assumed to be unpredictable. However, the empirical literature in the 1980s has found variables with predictive power to explain stock returns (see, e.g., Keim and Stambaugh, 1986; Campbell and Shiller, 1988; Fama and French, 1988, 1989). After strong evidence in favor of return predictability on the aggregate level in the 1990s and 2000s, recent empirical evidence considers that the predictability of stock return is rather weak (see, e.g., Ang and Bekaert, 2007; Cochrane, 2008; Lettau and Van Nieuwerburgh, 2008; Welch and Goyal, 2008). More precisely, the evidence for U.S. stock return predictability seems to be predominantly in-sample, but it is not robust to out-of-sample evaluations. ${ }^{1}$

The previous studies on stock return predictability evaluate the out-of-sample (OOS) forecasting using various approaches (see Table 1). A number of studies assess the OOS performance of the predictive regression models by comparing the OOS $\bar{R}^{2}$ suggested by Campbell and Thompson (2008) and/or the root mean square errors (RMSE). Obviously, simply comparing RMSE does not take into account the sample uncertainty underlying observed forecast differences. Therefore, recent studies use predictive ability tests (Welch and Goyal, 2008; Rapach et al., 2010; Westerlund and Narayan, 2012). Westerlund and Narayan (2012) use the equality predictive ability test proposed by Diebold and Mariano (1995) and the forecast encompassing test developed by Harvey et al. (1998) which compare OOS forecasts from non-nested models. A drawback of these tests is that they have a nonstandard distribution when comparing forecasts from nested models (see Clark and McCracken, 2001; McCracken, 2007). In order to account for the nested mod-

\footnotetext{
${ }^{1}$ Some studies addresses the issue of parameter instability by estimating regime-switching (e.g., Pastor and Stambaugh, 2001; Paye and Timmermann, 2006; Lettau and Van Nieuwerburgh, 2008; Dangl and Hallin, 2012), but this issue is out the scope of this paper.
} 
els Welch and Goyal (2008) and Westerlund and Narayan (2012) apply the MSEF and ENCNEW statistics of McCracken (2004), and Clark and McCracken (2001), respectively. The McCracken (2004) test statistic is a variant of the Diebold and Mariano (1995) statistic, while the Clark and McCracken (2001) test statistic is a variant of the Harvey et al. (1998) statistic. Rapach et al. (2010) use the MSPEadjusted statistic of Clark and West (2007) that is an adjusted version of the Diebold-Mariano statistic allowing to compare forecasts from nested linear models.

Methodologically, there are two limitations of the above-mentioned past studies that examine out-of-sample predictability. First, as mentioned in the previous section, the analysis based on point forecasts only is of limited value since the variability of prediction is not fully taken account (see Chatfield, 1993; and Christoffersen, 1998). Our paper contributes to the extant literature as the first study that adopts the prediction interval as a means of assessing stock return predictability. Secondly, the recent statement made by the American Statistical Association (Wasserstein and Lazar, 2016) expresses a serious concern on the use of $p$-value with an arbitrary threshold of 0.05 in many scientific research. In particular, they warn that "the widespread use of statistical significance (generally interpreted as $p$-value less than 0.05 ) as a license for making a claim of a scientific finding (or implied truth) leads to considerable distortion of the scientific process." We note that the past studies on return predictability (both in-sample and out-of-sample) rely heavily on the statistical significance based on $p$-value in establishing their findings. Our study based on prediction interval represents an estimation-based investigation which directly addresses the effect size of out-of-sample forecasting, which Wasserstein and Lazar (2016) suggest as a desirable alternative to statistical significance solely based on the $p$-value criterion.

\section{$3 \quad$ Methodology}

In this section, we present the models for stock return prediction and the methods for generating out-of-sample prediction interval. These models have simple linear structures and their specifications can be automatically determined by a fully datadependent method without an intervention of a researcher. Throughout the paper, we use AIC (Akaike's information criterion) to determine the unknown model orders. Let $Y_{t}$ denote the stock return and $X_{t}$ a predictor at time $t$. From the sample 
of size $n(t=1, \ldots, n)$, we generate a point forecast $Y_{n}(h)$ for the $h$-period ahead future value $Y_{n+h}$ of $Y$. A $h$-step ahead prediction interval with probability content $100(1-2 \theta) \%$ is denoted as $P I_{n}(h, \theta)$.

\subsection{Univariate autoregression}

We consider the $A R(p)$ model of the form

$$
Y_{t}=\alpha_{0}+\alpha_{1} Y_{t-1}+\ldots+\alpha_{p} Y_{t-p}+u_{t}
$$

where $u_{t}$ is an identically and independently (IID) distributed error term with zero mean and fixed variance. The model specifies that the stock return is predictable purely from its own past. An $A R(0)$ model with $\alpha_{i}=0$ for all $i(i=1, \ldots, p)$ is used as a naive model where past returns have no predictive power for the future return.

The unknown parameters are estimated using the least-squares (LS) method. The LS estimators for $\left(\alpha_{0}, \alpha_{1}, \ldots, \alpha_{p}\right)$ are denoted as $\left(\widehat{\alpha}_{0}, \widehat{\alpha}_{1}, \ldots, \widehat{\alpha}_{p}\right)$ and the LS residuals $\left\{\widehat{u}_{t}\right\}_{t=p+1}^{n}$. The point forecast for $Y_{n+h}(h=1,2, \ldots, H)$ is generated using the LS estimators as

$$
Y_{n}(h)=\widehat{\alpha}_{0}+\widehat{\alpha}_{1} Y_{n}(h-1)+\ldots+\widehat{\alpha}_{p} Y_{n}(h-p)
$$

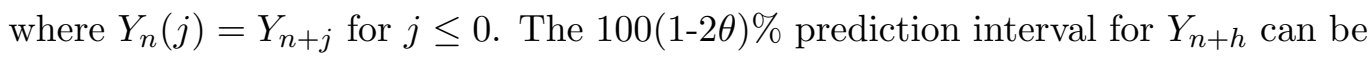
constructed based on the prediction mean-squared error $\left(M S E\left(Y_{n}(h)\right)\right)$, obtained using the delta method ${ }^{2}$ with the AR parameter estimators $\left(\widehat{\alpha}_{0}, \widehat{\alpha}_{1}, \ldots, \widehat{\alpha}_{p}\right)$ and assuming the normality of prediction error distribution, as

$$
P I_{n}(h, \theta ; A R) \equiv\left[Y_{n}(h)-z_{\tau} M S E\left(Y_{n}(h)\right), Y_{n}(h)+z_{\tau} M S E\left(Y_{n}(h)\right)\right],
$$

where $z_{\tau}$ is the $100(1-\tau) \%$ percentile of the standard normal distribution with $\tau=0.5 \theta$.

\subsection{Bootstrap prediction intervals}

The prediction intervals given in the previous subsection are constructed based on the assumption that the predictive error distribution follows a normal distribution.

\footnotetext{
${ }^{2}$ The delta method is a method of approximating the variance of the limiting distribution of a statistic (see, for example, Lutkepohl, 2005).
} 
The prediction MSE is calculated based on the delta method (Lutkepohl, 2005), which approximates the true variability based on asymptotic approximation. One may argue that the normality assumption is difficult to justify for stock return and that the delta method may provide inaccurate estimation of the true variability of the predictive distribution. In addition, in constructing the prediction interval, the conventional method does not account of estimation uncertainty. Hence, it is sensible to consider a non-parametric alternative which does not require the assumption of normality and asymptotic approximations.

The bootstrap is a method approximating the true sampling distribution of a statistic using the repetitive re-sampling the observed data, without imposing normality or resorting to asymptotic approximation (Thombs and Schucany, 1990; Pan and Politis, 2106). For the univariate AR model, the bootstrap method can be described as follows:

Generate the artificial set of data as

$$
Y_{t}^{*}=\widehat{\alpha}_{0}+\widehat{\alpha}_{1} Y_{t+1}^{*}+\ldots+\widehat{\alpha}_{p} Y_{t+p}^{*}+u_{t}^{*}
$$

where $\left(\widehat{\alpha}_{0}, \ldots, \widehat{\alpha}_{p}\right)$ are the LS estimators for $\left(\alpha_{0}, \ldots, \alpha_{p}\right)$ and $u_{t}^{*}$ is random draw with replacement from the LS residuals $\left\{\widehat{u}_{t}\right\}_{t=p+1}^{n}$. Note that we follow Thombs and Schucany (1990) to generate $\left\{Y_{t}^{*}\right\}_{t=1}^{n}$ based on the backward AR model using the last $p$ observation as the starting values. This is to accommodate the conditionality of the AR parameter estimators on the last $p$ values of the series. Using $\left\{Y_{t}^{*}\right\}_{t=1}^{n}$, the unknown AR parameters $\left(\alpha_{0}, \ldots, \alpha_{p}\right)$ are re-estimated, which are denoted as $\left(\widehat{\alpha}_{0}^{*}, \ldots, \widehat{\alpha}_{p}^{*}\right)$. The bootstrap replicates of the AR forecast for $Y_{n+h}$, made at time period $n$, are generated recursively as

$$
Y_{n}^{*}(h)=\widehat{\alpha}_{0}^{*}+\widehat{\alpha}_{1}^{*} Y_{n}^{*}(h-1)+\ldots+\widehat{\alpha}_{p}^{*} Y_{n}^{*}(h-p)+u_{n+h}^{*}
$$

where $Y_{n}^{*}(j)=Y_{n+j}$ for $j \leq 0$ and $u_{t}^{*}$ is random draw with replacement from $\left\{\widehat{u}_{t}\right\}_{t=p+1}^{n}$.

Repeat (4) and (5) many times, say $B$, to yield the bootstrap distribution for the AR forecast $\left\{Y_{n}^{*}(h ; j)\right\}_{j=1}^{B}$. This distribution is used as an approximation to the

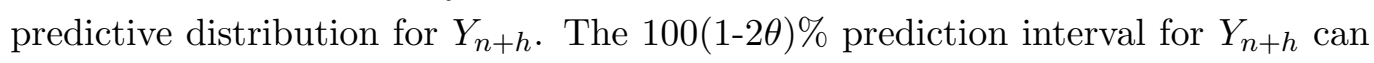
be constructed by taking appropriate percentiles from the bootstrap distribution. That is,

$$
P I_{n}\left(h, \theta ; A R^{*}\right) \equiv\left[Y_{n}^{*}(h, \tau), Y_{n}^{*}(h, 1-\tau)\right],
$$

where $Y_{n}^{*}(h, \tau)$ is $100 \tau \%$ percentile from $\left\{Y_{n}^{*}(h ; j)\right\}_{j=1}^{B}$ and $\tau=0.5 \theta$. 


\subsection{Predictive regression: IARM}

We consider a predictive model for stock return $Y$ as a function of a predictor $X$ with lag order $p$, which can be written as

$$
\begin{aligned}
& Y_{t}=\beta_{0}+\beta_{1} X_{t-1}+\ldots+\beta_{p} X_{t-p}+v_{1 t} \\
& X_{t}=\delta_{0}+\delta_{1} X_{t-1}+\ldots+\delta_{p} X_{t-p}+v_{2 t} .
\end{aligned}
$$

It is assumed that the error terms are IID with fixed variances and covariances: $\operatorname{Var}\left(v_{1 t}\right) \equiv \sigma_{1}^{2}, \operatorname{Var}\left(v_{2 t}\right) \equiv \sigma_{2}^{2}$ and $\operatorname{Cov}\left(v_{1 t}, v_{2 t}\right) \equiv \sigma_{12}$.

It is well-known that the LS estimators for $\left(\beta_{1}, \ldots, \beta_{p}\right)$ are biased in small samples, as long as $\sigma_{12} \neq 0$. It is because the LS estimators completely ignore the presence of $\sigma_{12}$, as Stambaugh (1999) points out. Amihud et al. (2004, 2008, 2010) propose a bias-correction method based on a augmented regression, called the augmented regression method (ARM), which is subsequently improved by Kim (2014).

The method assume that the error terms in (7) and (8) are linearly related as $v_{1 t}=\phi v_{2 t}+e_{t}$ where $e_{t}$ is an independent normal error term with a fixed variance. It involves running the regression for $Y$ against lagged $X$ 's as in (7), augmented with the bias-corrected residuals from the predictor equations (8). That is, we run the regression of the form

$$
Y_{t}=\beta_{0}+\beta_{1} X_{t-1}+\ldots+\beta_{p} X_{t-p}+\phi \hat{v}_{2 t}^{c}+e_{t}
$$

where $\widehat{v}_{2 t}^{c} \equiv X_{t}-\widehat{\delta}_{0}^{c}-\widehat{\delta}_{1}^{c} X_{t-1}-\ldots-\widehat{\delta}_{p}^{c} X_{t-p}$, while $\left(\widehat{\delta}_{0}^{c}, \widehat{\delta}_{1}^{c}, \ldots, \widehat{\delta}_{p}^{c}\right)$ are the bias-corrected estimators for $\delta_{i}$ 's. Amihud et al. (2010) use the asymptotic formulae derived by Shaman and Stine (1988) to obtain these bias-corrected estimators. The biascorrected estimators $\left(\widehat{\beta}_{0}^{c}, \widehat{\beta}_{1}^{c}, \ldots, \widehat{\beta}_{p}^{c}\right)$ for $\left(\beta_{0}, \beta_{1}, \ldots, \beta_{p}\right)$ are obtained by regressing the augmented regression (9).

Kim (2014) proposes three modifications to the ARM of Amihud et al. (2010). The first is the bias-correction method of a higher order accuracy than the one used by Amihud et al. (2010). The second is the use of stationarity-correction (Kilian, 1998), which ensures that the bias-corrected estimators satisfy the condition of stationarity. This correction is important because bias-correction often makes the parameter estimates of the model (7) and (8) imply non-stationarity of stock return. The third is the use of matrix formula for bias-correction, which makes the implementation of the ARM for a higher order model computationally 
easier. According to the Monte Carlo study of Kim (2014), the improved ARM (IARM) provides more accurate parameter estimation and statistical inference than its original version in small samples.

The point forecast for stock return based on the IARM is generated jointly with that of the predictor as

$$
Y_{n}(h)=\widehat{\beta}_{0}^{c}+\widehat{\beta}_{1}^{c} X_{n}(h-1)+\ldots+\widehat{\beta}_{p}^{c} X_{n}(h-p)
$$

where $X_{n}(h)=\widehat{\delta}_{0}^{c}+\widehat{\delta}_{1}^{c} X_{n}(h-1)+\ldots+\widehat{\delta}_{p}^{c} X_{n}(h-p)$ and $X_{n}(j)=X_{n+j}$ for $j \leq 0$. The $100(1-2 \theta) \%$ prediction interval for $Y_{n+h}$ can be constructed based on the prediction mean-squared error $\left(M S E\left(Y_{n}(h)\right)\right)$ obtained using the delta method with IARM parameter estimators and assuming the normality of prediction error distribution. That is,

$$
P I_{n}(h, \theta ; I A R M) \equiv\left[Y_{n}(h)-z_{\tau} M S E\left(Y_{n}(h)\right), Y_{n}(h)+z_{\tau} M S E\left(Y_{n}(h)\right)\right] .
$$

\subsection{Vector Autoregressive Model}

The predictive model given (7) and (8) specifies that the stock return depends only on the past value of a predictor. This means that the model allows for only oneway causality from the predictor to stock return, and that the stock return does not depend on the past value of its own. These restrictions may deliver a simple and parsimonious model, but they completely exclude the possibility stock return depending on its own past and the potential feedback effect from stock return to the predictor. A more general model can be specified by resorting to the vector autoregressive (VAR) model, which can be written as

$$
\begin{aligned}
& Y_{t}=\tau_{0}+\alpha_{1} Y_{t-1}+\ldots+\alpha_{p} Y_{t-p}+\beta_{1} X_{t-1}+\ldots+\beta_{p} X_{t-p}+u_{1 t} \\
& X_{t}=\tau_{0}+\gamma_{1} Y_{t-1}+\ldots+\gamma_{p} Y_{t-p}+\delta_{1} X_{t-1}+\ldots+\delta_{p} X_{t-p}+u_{2 t} .
\end{aligned}
$$

The model is widely used for modeling and forecasting stock return dynamically inter-related with other predictors (see, for example, Engsted and Pedersen, 2012).

The LS estimator for the unknown parameters in (12) and (13) are biased in small samples, which can provide biased prediction intervals. In this paper, we employ the bias-correction based on the asymptotic formula given by Nicholls and Pope (1988), which is also used by Engstead and Pedersen (2012). We also apply 
Killian's (1998) stationarity correction in case the bias-correction provides parameter estimates which imply non-stationarity. Using these bias-corrected estimators, the point forecasts are generated recursively as

$$
\begin{aligned}
& Y_{n}(h)=\widetilde{\tau}_{0}+\widetilde{\alpha}_{1} Y_{n}(h-1)+\ldots+\widetilde{\alpha}_{p} Y_{n}(h-p)+\widetilde{\beta}_{1} X_{n}(h-1)+\ldots+\widetilde{\beta}_{p} X_{n}(h-p)(14 \\
& X_{n}(h)=\widetilde{\tau}_{0}+\widetilde{\gamma}_{1} Y_{n}(h-1)+\ldots+\widetilde{\gamma}_{p} Y_{n}(h-p)+\widetilde{\delta}_{1} X_{n}(h-1)+\ldots+\widetilde{\delta}_{p} X_{n}(h-p) .
\end{aligned}
$$

where $X_{n}(j)=X_{n+j}$ for $j \leq 0, Y_{n}(j)=Y_{n+j}$ for $j \leq 0$, and the parameters with tilde indicates the bias-corrected estimator for the corresponding parameters.

The 100(1-2 $\theta) \%$ prediction interval for $Y_{n+h}$, constructed based on the prediction mean-squared error $\left(M S E\left(Y_{n}(h)\right)\right)$ obtained using the delta method with the VAR bias-corrected parameter estimators and assuming the normality of prediction error distribution, is denoted as

$$
P I_{n}(h, \theta ; V A R) \equiv\left[Y_{n}(h)-z_{\tau} M S E\left(Y_{n}(h)\right), Y_{n}(h)+z_{\tau} M S E\left(Y_{n}(h)\right)\right] .
$$

\section{Data and Computational Details}

In this section, we provide the data and computational details, along with the simple illustrative examples in relation to interval forecasting and their assessment.

\subsection{Data}

We use the financial variables compiled by Welch and Goyal (2008) for the U.S. stock market, available from Amit Goyal's website. The precise definitions of these variables are given in Welch and Goyal (2007). For stock return, we use the CRSP NYSE value-weighted return, which is widely used as a benchmark for investment and academic research. These financial variables (monthly from 1926 to 2014, except for NTIS which starts from 1927) are listed as below:

- Dividend-Yield (DY)

- Dividend-Price Ratio (DP)

- Earnings-Price Ratio (EP)

- Dividend Payout Ratio (DE)

- Book-to-Market (BM) 
- Risk-free rate $(\mathrm{RF})$

- Inflation (INF)

- Stock Variance (SVAR)

- Long Term Yield (LTY)

- Long Term Return (LTR)

- Net Equity Expansion (NTIS)

- Default Return Spread (DFR)

- Default Yield Spread (DFY)

- Term Spread (TMS)

We add three economic variables (monthly from 1927 to 2014) to those proposed by Welch and Goyal (2008):

- Industrial production growth (IPG)

- Output gap (GAP)

- Economic policy uncertainty (EPU)

The data used to construct the industrial production growth and the output gap are downloaded from the FRED database of St Louis Fed. Following Schrimpf (2010) we construct the output gap measure by applying the filter by Hodrick and Prescott (1997) to the logarithmic series of industrial production. The smoothing parameter is set to 128,800 (monthly data). The cyclical component of the series is taken as the output gap. The index of economic policy uncertainty (EPU) is proposed by Baker et al. (2015), built on three components: (i) the frequency of newspaper references to economic policy uncertainty, (ii) the number of federal tax code provisions set to expire, and (iii) the extent of forecaster disagreement over future inflation and government purchases. ${ }^{3}$

\subsection{Computational Details}

Evaluation of alternative out-of-sample prediction intervals is conducted in a purely empirical setting using the realized future values. For evaluation free from data

\footnotetext{
${ }^{3}$ See Baker et al. (2015) for a detailed description of the historical EPU index.
} 
snooping bias, we apply moving sub-sample windows to the above data set, adopting a grid of different estimation window lengths ranging from 24 months to 240 months (with an increment of 24 months). From each estimation window, 12-step ahead (out-of-sample) prediction intervals are generated from a predictive model. For example, when the window length of 24 months, we take the first 120 observations from January 1926 to estimate the model, and generate 12-step ahead forecasts. And then we move to the next set of 120 observations from February 1926 to estimate the model and generate forecasts. This continues until the end of the data set is reached.

As a means of comparison, we use the coverage rate and the interval score proposed by Gneiting and Raftery (2007, p.370). Let a $100(1-2 \theta) \% h$-step ahead prediction interval be given by $\left[L_{h}, U_{h}\right]$. The coverage rate is calculated as the proportion of the true values covered by the prediction interval, i.e.,

$$
C(h)=\frac{\sharp\left(L_{h} \leq Y_{h} \leq U_{h}\right)}{N},
$$

where $Y_{h}$ is the true future value, $N$ is the total number of prediction intervals for forecast horizon $h$, and $\sharp$ indicates the frequency at which the condition inside the bracket is satisfied. A $100(1-2 \theta) \%$ prediction interval is expected to have $C(h)$ value of $(1-2 \theta)$ in repeated sampling.

The interval score for a $100(1-2 \theta) \%$ interval $\left[L_{h}, U_{h}\right]$, it is given by

$$
S_{\theta}\left(L_{h}, U_{h} ; Y_{h}\right)=\left(U_{h}-L_{h}\right)+\frac{1}{\theta}\left(L_{h}-Y_{h}\right) I\left(Y_{h}<L_{h}\right)+\frac{1}{\theta}\left(Y_{h}-U_{h}\right) I\left(Y_{h}>U_{h}\right)
$$

where $I(\cdot)$ is an indicator function which takes 1 if the condition inside the bracket is satisfied and 0 if otherwise; and $Y_{h}$ is the true future value. If the interval covers $Y_{h}$, the score takes the value of its length; if otherwise, a penalty term is added to the value of length, which is how much the interval misses $Y_{h}$ scaled by $1 / \theta$. In the event that the interval misses $Y_{h}$ by a small (large) margin, a light (heavy) penalty is imposed. The interval score measures the quality of the probabilistic statement implied by a prediction interval. We note that the interval score is far more informative than the coverage rate, since it takes full account of the accuracy and riskiness of a prediction interval. In fact, the dichotomous nature of the coverage rate may deliver misleading assessment of predictive accuracy, as the examples in the next subsection show. Hence, in this paper, we use both measures, but giving more importance to the interval score. 


\subsection{Examples}

In this subsection, we present three simple illustrative examples. The first highlights the reason as to why evaluation of point forecasts only is an incomplete exercise in assessing predictability; while the other two explain why the interval score $S_{\theta}$ is a more informative measure of predictive quality than the coverage rate $C(h)$ presented in Section 4.2.

Consider a set of future values $\left(y_{1}, y_{2}, y_{3}, y_{4}, y_{5}\right)=(0,0,0,0,0)$, along with two sets of $80 \%$ prediction intervals $P I_{1}$ and $P I_{2}$ generated from two alternative models (called Model 1 and Model 2):

\section{Example 1: Point Forecasting versus Interval Forecasting}

$$
\begin{gathered}
P I_{1}=[(-1,1),(-1,1),(1,2),(-1,1),(-1,1)] \\
P I_{2}=[(-2,2),(-2,2),(0.5,2.5),(-2,2),(-2,2)]
\end{gathered}
$$

For the purpose of simplicity, suppose that Models 1 and 2 generate the identical point forecasts, which means that the two appear to show the predictive accuracy of the same degree if evaluation is carried out using the point forecasts only. However, Model 2 generates prediction intervals twice wider than Model 1, indicating that its prediction is twice riskier than that of Model 1. In this case, Model 1 should be clearly preferred for the purpose of forecasting. If Model 2 includes an information set additional to that of Model 1, the extra information does not improve the quality of prediction but only increases its variability. An important point is that comparison based on point forecasts is not capable of capturing the difference in forecast variability.

\section{Example 2: Coverage Rate versus Interval Score}

$$
\begin{gathered}
P I_{1}=[(-1,1),(-1,1),(1,2),(-1,1),(-1,1)] \\
P I_{2}=[(0.1,0.2),(-0.2,-0.1),(0.1,0.2),(-0.2,-0.1),(0.1,0.2)]
\end{gathered}
$$

$P I_{1}$ covers the true values $(y)$ four out of five times, with the correct coverage rate of 0.8 ; while $\mathrm{PI}_{2}$ never covers the true value and its coverage rate is 0 . If one adopts the coverage rate as a means of comparison, the Model 1 should be preferred. However, the mean interval score of $P I_{1}$ is 3.8 and that of $P I_{2}$ is 1.1 , which means that Model 2 delivers a more informative and higher-quality prediction. This is 
because $\mathrm{PI}_{2}$ 's are much tighter, only narrowly missing the true values. In contrast, $P I_{1}$ 's are too wide and uninformative. In this case, the coverage rate fails to capture the richer informative quality of $P I_{2}$.

\section{Example 3: Coverage Rate versus Interval Score}

$$
\begin{aligned}
& P I_{1}=[(-0.5,0.5),(-0.5,0.5),(1.5,2.5),(-0.5,0.5),(-0.5,0.5)] \\
& P I_{2}=[(-0.5,0.5),(-0.5,0.5),(0.1,1.1),(-0.5,0.5),(-0.5,0.5)]
\end{aligned}
$$

$P I_{1}$ and $P I_{2}$ have the correct coverage rate of 0.8 and identical lengths. However, the mean interval score of $P I_{1}$ is 4 while that of $P I_{2}$ is 1.2 . This is because $P I_{1}$ misses by big margin when it fails to cover the true value, while $P I_{2}$ misses it only with a small margin. As before, the coverage rate does not fully reflect the informative quality of prediction interval because it is unable to capture the effect of a big miss (which can be costly economically), while the interval score is capable of including this costly miss in its evaluation.

\section{Empirical Results}

Given the large number of possible predictors for stock return and the prediction models being considered, we report only a set of selective but representative results. This is to simplify the exposition and to present the results in a manageable way. However, we note that qualitatively similar results are obtained from those unreported. Figure 1 plots the examples of $50 \%$ and $95 \%$ prediction intervals for stock return, 1-step ahead from 1936:01 to 2014:12 generated with rolling window of length 120. The first figure plots those from the $\mathrm{AR}(0)$ model and the second those from the IARM with the dividend yield (DY) as a predictor. As might be expected, $95 \%$ intervals are wider but less informative, while $50 \%$ intervals are tighter but riskier with a higher chance of missing the true values. The width of the intervals changes over time, wider during the periods of higher volatility. The main question of the paper is whether additional information included in the predictive model can improve the informative quality of prediction intervals for stock return.

We first check whether the prediction intervals provide reasonable coverage properties by employing the likelihood ratio (LR) test for the conditional efficiency 
of prediction interval proposed by Christoffersen (1998). It is based on the property that, for $100(1-2 \theta) \%$ prediction intervals to be efficient (conditionally on the past information), the indicator variable for their coverage should follow the independent Bernoulli distribution with parameter 1-20. Christoffersen (1998) develops the LR test for the joint null hypothesis for the coverage rate (1-2 $\theta)$ and independence, which asymptotically follows the chi-squared distribution with 2 degrees of freedom. Figure 2 plots the LR statistics for the prediction intervals from $\mathrm{AR}(0)$ model given in Figure 1, using the rolling sub-sample window of 120 observations. For the 50\% intervals, the joint hypothesis is rejected at $1 \%$ level of significance only occasionally over time; while for the $95 \%$ intervals, the hypothesis cannot be rejected at the $1 \%$ level over the entire period. Testing at the $5 \%$ level provides similar results. This indicates that the prediction intervals generated from the $\mathrm{AR}(0)$ model show reasonable coverage properties over time. We note that those generated from the other models (such as the IARM with the predictor DY) provide similar results.

We now pay attention to the interval score properties of alternative prediction intervals. As we have seen in the previous section, the interval score is a more complete measure for the quality of prediction interval than the coverage rate. Figure 3 reports the mean interval score of all prediction intervals for forecast horizon $h$ from 1 to 12. The multivariate models (IARM and VAR) have the predictor DY. When the window length is 24 , the mean score of the $\operatorname{AR}(0)$ and $\operatorname{AR}(p)$ models are the smallest for all forecast horizons, for both cases of $50 \%$ and $95 \%$ prediction intervals. When the window length is 120 , again the univariate prediction intervals show better performance than the multivariate ones in most cases. Hence, there is no clear evidence that inclusion of DY improves the predictability of stock return. In fact, the VAR model (which has the most general dependency structure) provides prediction intervals with the lowest quality in terms of the interval score.

Figure 4 reports the mean interval score averaged across all forecast horizon (median) for all prediction intervals. These median of mean interval scores are plotted against the window length from 24 to 240. As before, the multivariate models have the DY as a predictor. Again, the prediction intervals generated from the univariate models outperform those from the multivariate models for nearly all window lengths. Hence, the evidence suggests that the use of DY as a predictor does not improve predictability of stock return. It can also be observed that the accuracy improves with the sample size only to a certain point. For example, when the nominal coverage is 0.95 , the mean score nearly hits the bottom when the sam- 
ple size (or window length) is around 100, for both cases of $50 \%$ and $95 \%$ prediction intervals. In addition, as is also clear from Figure 3, we find no evidence that the bootstrap prediction intervals perform better than those generated from $\operatorname{AR}(0)$ or $\operatorname{AR}(p)$ models. This suggests that the prediction intervals based on the conventional normal approximation to the predictive distribution perform adequately for monthly stock return.

In Figure 5, the mean interval scores of the $\operatorname{AR}(0)$ model are compared with those from the IARM with different predictors including DY, DP, EP, BM, PE, inflation rate, and risk-free rate, for forecast horizons $1,4,8$, and 12 . For $\mathrm{h}=$ 1 , the $\operatorname{AR}(0)$ model shows smaller mean interval scores than the IARM for most cases, especially when the length of rolling window is short. When forecast horizon is long ( $\mathrm{h}=8$ or 12 ), there are occasions where the prediction intervals from IARM beat those from the $\operatorname{AR}(0)$, but the margins are fairly small. When the rolling window length is greater than 120 , the performances of the alternative prediction intervals are almost indistinguishable. That is, there is no compelling evidence that the IARM with a range of predictors beats $\operatorname{AR}(0)$ model in terms of the interval score.

Figure 6 plots the mean interval scores from the economic variables (IPG, GAP, and EPU) based on the IARM for the forecast horizons 1, 4, 8, and 12, in comparison with the score from the $\operatorname{AR}(0)$ model. Again, there is little evidence that the economic indicators help generate prediction intervals that are of higher quality than those from the $\mathrm{AR}(0)$ model. There are occasions where the mean interval score from an economic variable is lower than that of $\mathrm{AR}(0)$ model, but the marginal improvement is fairly small. As also observed in Figure 5, when $h=1$ and the window length is short, the AR(0) model is the clear winner. This means that, for short-term and short-horizon prediction of stock return, the naive $\operatorname{AR}(0)$ model provides the prediction intervals of the highest quality.

Figure 7 plots time variation of interval score when the window length is 120 and $h=1$, for the $\operatorname{AR}(0)$ model and IARM with selected predictors. The spikes represent the failure of prediction interval in predicting the future stock return. It appears that all prediction intervals show similar pattern over time, showing the spikes at the times of stock market volatility, such as late 30's, early 60's, oil shock, and stock market crashes $(1987,2008)$. There is no clear evidence that any predictors from the IARM generate more accurate than $\operatorname{AR}(0)$ model. In comparison with the NBER recession and boom dates, we observe that the times 
of predictive failure are not related with the business cycle.

The empirical results shown that there is no clear indication that the multivariate model with predictors beats the most simple and naive $\mathrm{AR}(0)$ model, in terms of predictive accuracy and informative quality of prediction intervals. This finding points to the conclusion that the stock return has been unpredictable in the U.S. market and that the stock market has been informationally efficient in the weak and semi-strong form, subject to the information set under investigation in this study.

\section{Concluding Remarks}

This paper contributes to the extant literature of stock return predictability, as the first study that adopts prediction interval as a measure of out-of-sample predictability. Past studies exclusively used point forecasts, which are of limited value in assessing predictability of stock return which often shows a high degree of volatility over time. A point forecast is an estimate of the mean of the predictive distribution, which carries no information about its variability. A more complete analysis of predictive distribution can be achieved by evaluating prediction intervals (see Chatfield, 1993; Christoffersen, 1998, and Pan and Politis, 2015). We consider prediction intervals for monthly stock return generated from a range of linear models with different degrees of information content. They include a naive model, simple linear univariate autoregressive models, and multivariate (predictive regression and vector autoregressive model). For the latter, we use a range of economic and financial variables as possible predictors for stock return. We also consider the bootstrap prediction interval which relies on a non-parametric method and does not require the assumption of normality. In view of the recent statement made by the American Statistical Association which expresses serious concerns on the research practice heavily based on statistical significance (Wasserstein and Lazar, 2016), our study represents an attempt to address the issue of stock return predictability based on an estimation-based approach. In contrast, the past studies rely heavily on statistical significance using the $p$-value as an indicator.

Using the data set compiled by Welch and Goyal (2007) with three additional economic variables, we evaluate and compare out-of-sample and multi-step prediction intervals from alternative models in a purely empirical setting, using moving- 
subsample windows of different lengths. The mean coverage rate and interval score are used as the measures for predictive accuracy and quality of prediction intervals. We find that all models considered provide prediction intervals with reasonable coverage properties. In terms of the interval score, we find that the $\operatorname{AR}(0)$ model, which is the most naive model, provides the prediction intervals that often outperform those generated from its univariate and multivariate alternatives. We find no clear indication that univariate autoregression and multivariate models provide prediction intervals of higher quality than those from the $\operatorname{AR}(0)$. That is, we find little evidence that predictability of stock return is improved by incorporating the past history of its own and that of its predictors. The evidence suggests that the U.S. stock market has been efficient in the weak-form as well as in the semi-strong form, subject to the information set considered in this study.

There are two further issues that future studies may explore. First, the predictors not considered in this study may be examined. The universe of possible predictors for stock return is expansive, and we are calling for additional future studies to evaluate their predictive power in the context of interval forecasting. For example, recent studies (based on point forecasting) report that technical indicators show a higher degree of predictability than financial ratios (see, for example, Neely et al., 2014). Since we are limited by data availability for technical indicators due to the historical span of the dataset in this study, future studies may assess the predictive power of technical indicators for interval forecasting of stock return. Second, only the prediction intervals generated from linear time series models are considered in this study. It is possible that stock returns show non-linear dependence on past information (see Hinich and Patterson, 1985), while this possibility has not been extensively investigated in the empirical literature of stock return predictability. In addition to the difficulty of finding a suitable non-linear model for stock return, we note that construction of prediction interval from a non-linear model is a technically and computationally challenging exercise (see, for example, Frances and van Dijk, 2000). On this basis, this line of research is left as a possible future study. 


\section{References}

[1] Amihud, Y., Hurvich, C.M., 2004. Predictive regression: A reduced-bias estimation method. Journal of Financial and Quantitative Analysis, 39, 813841.

[2] Amihud, Y., Hurvich, C.M., Wang, Y., 2008. Multiple-predictor regressions: Hypothesis testing. Review of Financial Studies, 22, 413434.

[3] Amihud, Y., Hurvich, C.M., Wang, Y., 2010. Predictive regression with orderp autoregressive predictors. Journal of Empirical Finance, 17, 513525.

[4] Ang, A., Bekaert, G., 2007. Stock return predictability: Is it there? Review of Financial Studies, 20, 651-707.

[5] Baker, S.R., Bloom, N., and Davis S.J., 2015. Measuring Economic Policy Uncertainty, Working paper No 21633, NBER.

[6] Bali, T.G., Zhou, H., 2016. Risk, uncertainty, and expected returns. Journal of Financial and Quantitative Analysis, forthcoming.

[7] Bekaert, G., Engstrom, E., Xing, Y., 2009. Risk, uncertainty, and asset prices. Journal of Financial Economics, 91, 59-82.

[8] Brogaard, J., Detzel, A., 2015. The asset pricing implications of government economic policy uncertainty. Management Science, 61, 3-18.

[9] Campbell, J.Y., Shiller, R.J., 1988. Stock prices, earnings, and expected dividends. Journal of Finance, 43, 661-76.

[10] Campbell, J.Y., Thompson, S.B., 2008. Predicting the equity return premium out of sample: Can anything beat the historical average? The Review of Financial Studies, 21, 1509-1531.

[11] Chatfield, C., 1993. Calculating interval forecasts. Journal of Business and Economic Statistics, 11(2), 121-135.

[12] Christoffersen, P.F., 1998. Evaluating interval forecasts. International Economic Review, 39, 841-862.

[13] Clark, T., West, K., 2007. Approximately normal tests for equal predictive accuracy in nested models. Journal of Econometrics, 138, 291-311.

[14] Cochrane, J.H., 2008. The dog that did not bark: A defence of return predictability. Review of Financial Studies, 21, 1533-1575. 
[15] Cooper, I., Priestley, R., 2009. Time-varying risk premia and the output gap. Review of Financial Studies, 22, 2801-2833.

[16] Dangl, T., Halling, M., 2012. Predictive regressions with time-varying coefficients. Journal of Financial Economics, 106, 157-181.

[17] De Gooijer, J., Hyndman, R.J., 2006. 25 years of time series forecasting. International Journal of Forecasting, 22, 443473.

[18] Diebold, F., Mariano, R., 1995. Comparing predictive accuracy. Journal of Business and Economic Statistics, 13, 253-263.

[19] Engsted, T., Pedersen, T.Q., 2012. Return predictability and intertemporal asset allocation: Evidence from a bias-adjusted VAR model. Journal of Empirical Finance, 19, 241-253.

[20] Fama, E. F., K. R. French., 1988. Dividend yields and expected stock returns. Journal of Financial Economics, 2(1), 3-25.

[21] Fama, E. F., K. R. French., 1989. Business conditions and expected returns on stocks and bonds. Journal of Financial Economics, 25(1), 23-49.

[22] Frances, P.H. van Dijk, D., 2000. Non-Linear Time Series Models in Empirical Finance, Cambridge University Press, Cambridge.

[23] Gneiting, T., Raftery, A.E., 2007. Strictly proper scoring rules, prediction, and estimation. Jourmal of American Statistical Association, 102, 359378.

[24] Harvey D.I., Leybourne S.J., Newbold P., 1998. Tests for forecast encompassing. Journal of Business and Economic Statistics, 16, 254-259.

[25] Hinich, M.J., Patterson, D.M., 1985. Evidence of nonlinearity in daily stock returns. Journal of Business and Economic Statistics, 3, 69-77.

[26] Hodrick, R.J., Prescott, E., 1997. Postwar U.S. business cycles: An empirical investigation. Journal of Money, Credit and Banking, 29, 1-16.

[27] Keim, D.B., Stambaugh R.F., 1986. Predicting returns in the stock and bond markets. Journal of Financial Economics, 17(2), 357-90.

[28] Kim, J.H., 2014. Predictive regression: An improved augmented regression method. Journal of Empirical Finance, 26, 13-25.

[29] Kim. J.H., 2015. VAR.etp: VAR modelling: estimation, testing, and prediction. $\mathrm{R}$ package version 0.61. URL: http://cran.rproject.org/web/packages/VAR.etp/index.html 
[30] Kilian, L. 1998. Small-sample confidence intervals for impulse response functions. The Review of Economics and Statistics, 80(2), 218-230.

[31] Kilian, L. 1999. Exchange rates and monetary fundamentals: What do we learn from long-horizon regressions? Journal of Applied Econometrics, 14, 491-510.

[32] Lettau, M., Van Nieuwerburgh, S., 2008. Reconciling the return predictability evidence. The Review of Financial Studies, 21(4), 1607-1652.

[33] Lewellen, J., 2004. Predicting returns with financial ratios. Journal of Financial Economics, 74, 209-235.

[34] L utkepohl, H., 2005. New Introduction to Multiple Time Series Analysis. Springer.

[35] Mark, N.C., 1995. Exchange rates and fundamentals: Evidence on longhorizon predictability. American Economic Review, 85, 201-218.

[36] Merton, R.C., 1969. Lifetime portfolio selection under uncertainty: The continuous-time case. The Review of Economics and Statistics, 51 (3), 247-57.

[37] Neely, C.J., Rapach, D.E., Tu, J., Zhou, G., 2014. Forecasting the equity risk premium: The role of technical indicators. Management Science, 60, 17721791.

[38] Nelson, C., Kim, M., 1993. Predictable stock return: The roles of small sample bias. The Journal of Finance, 48, 641-661.

[39] Nicholls, D.F., Pope, A.L., 1988. Bias in the estimation of multivariate autoregressions. Australian \& New Zealand Journal of Statistics, 30A, 296-309.

[40] Pan, L., Politis, D.N., 2016. Bootstrap prediction intervals for linear, nonlinear and nonparametric autoregressions. Journal of Statistical Planning and Inference, forthcoming. Available online 7 November 2014, ISSN 0378-3758, http://dx.doi.org/10.1016/j.jspi.2014.10.003.

[41] Pastor, L., Stambaugh, R.F., 2001. The equity premium and structural breaks. The Journal of Finance, 56, 1207-1239.

[42] Paye, B.S., Timmermann, A., 2006. Instability of return prediction models. Journal of Empirical Finance, 13, 274-315. 
[43] Rapach, D.E., Strauss, J.K., Zhou, G., 2010. Out-of-sample equity premium prediction: Combination forecasts and links to the real economy. The Review of Financial Studies, 23, 821-862.

[44] Rapach, D.E., Strauss, J.K., Zhou, G., 2013. International stock return predictability: What is the role of the United States? The Journal of Finance, 68, 1633-1662.

[45] R Core Team, 2015. R: A language and environment for statistical computing. R Foundation for Statistical Computing, Vienna, Austria. URL http://www.R-project.org/.

[46] Samuelson, P.A., 1965. Proof that properly anticipated price fluctuate randomly. Industrial Management Review, 6(2), 41-43.

[47] Samuelson, P.A., 1969. Lifetime portfolio selection by dynamic stochastic programming. The Review of Economics and Statistics, 51(3), 239-46.

[48] Schrimpf, A., 2010. International stock return predictability under model uncertainty. Journal of International Money and Finance, 29, 1256-1282.

[49] Stambaugh, R.F., 1999. Predictive regressions. Journal of Financial Economics, 54, 375-421.

[50] Thombs, L.A., Schucany, W.R., 1990. Bootstrap prediction intervals for autoregression. Journal of the American Statistical Association, 85, 486-492

[51] Wasserstein R. L. Lazar, N. A. 2016, The ASA's statement on pvalues: Context, process, and purpose, The American Statistician, DOI: 10.1080/00031305.2016.1154108

[52] Welch, I., Goyal, A., 2008. A Comprehensive look at the empirical performance of equity premium prediction. The Review of Financial Studies, 21(4), 14551508.

[53] Westerlund, J., Narayan, P.K., 2012. Does the choice of estimator matter when forecasting returns? Journal of Banking and Finance, 36, 2632-2640.

[54] Westerlund, J., Narayan, P.K., 2015. Testing for predictability in conditionally heteroskedastic stock returns. Journal of Financial Econometrics, 13, 342-375. 


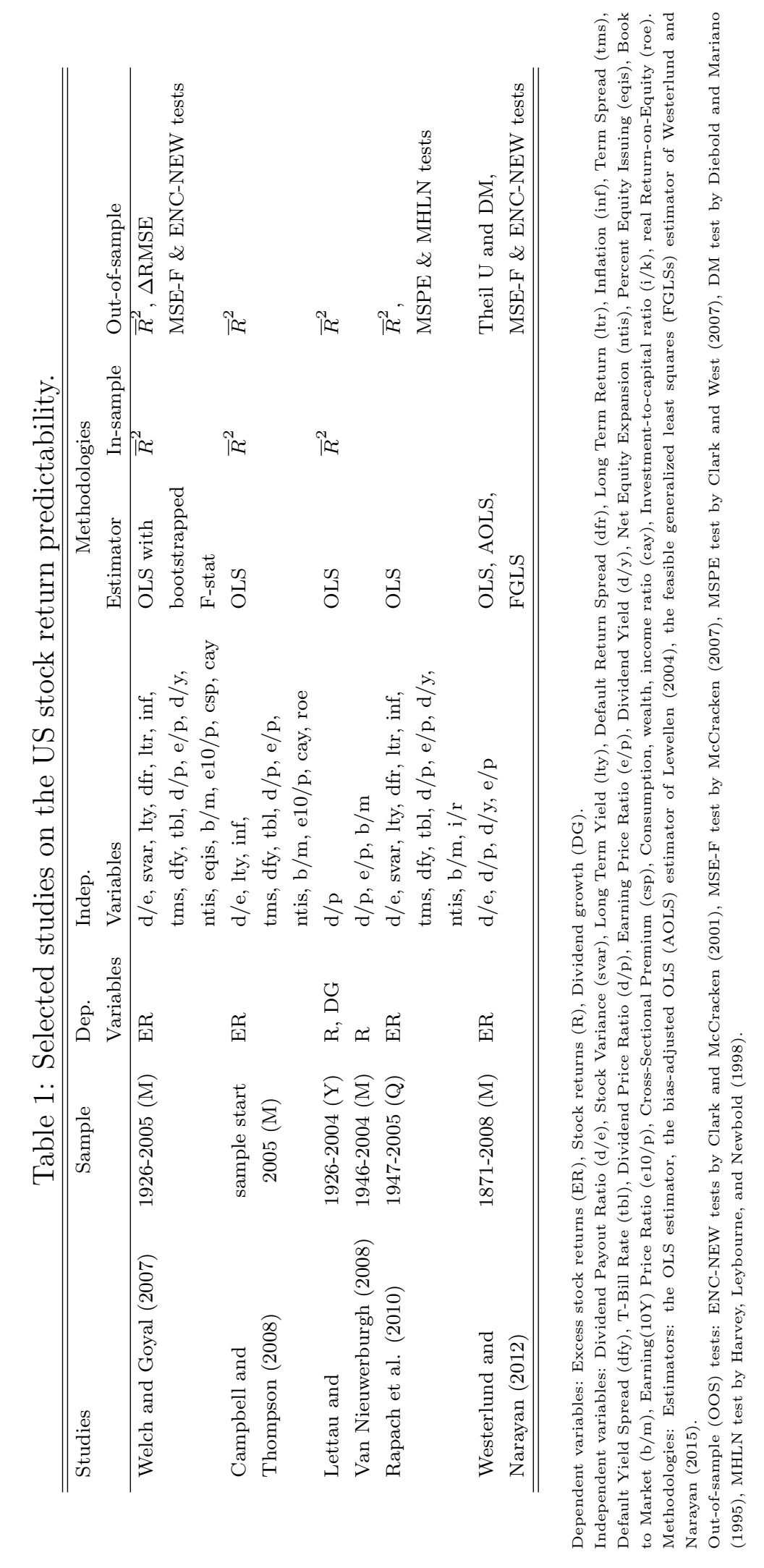


Figure 1. Examples of Prediction Intervals ( $50 \%$ and $95 \%$, h=1, rolling window size $=120$ )
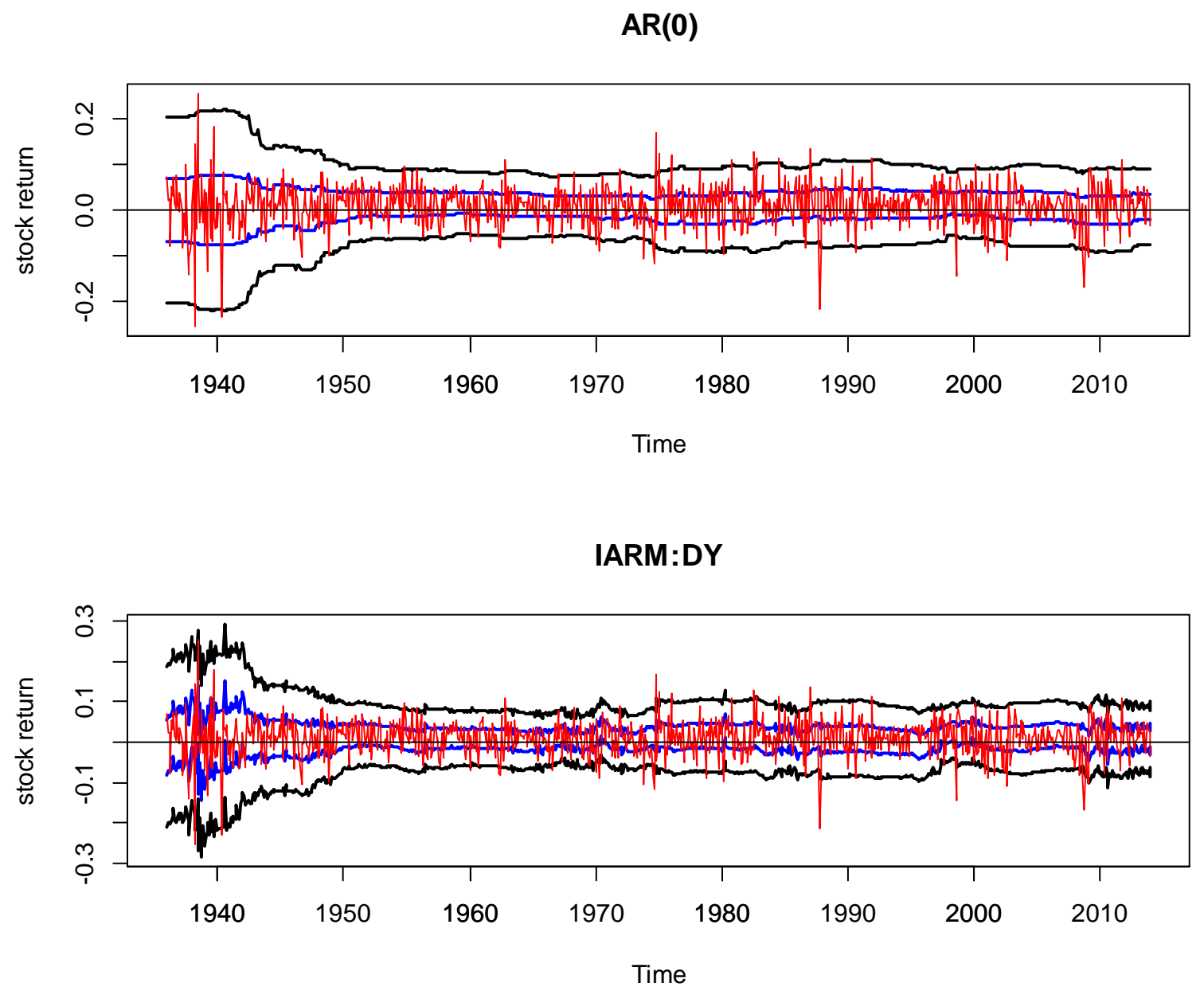

The black lines represent 95\% prediction intervals, the blue lines 50\% intervals, and the red line indicates the stock return. 
Figure 2. Likelihood Ratio Test Statistic for Prediction Intervals from AR(0) model (rolling window size $=120$ )

\section{$50 \%$ Prediction Interval, $\mathrm{h}=1$}

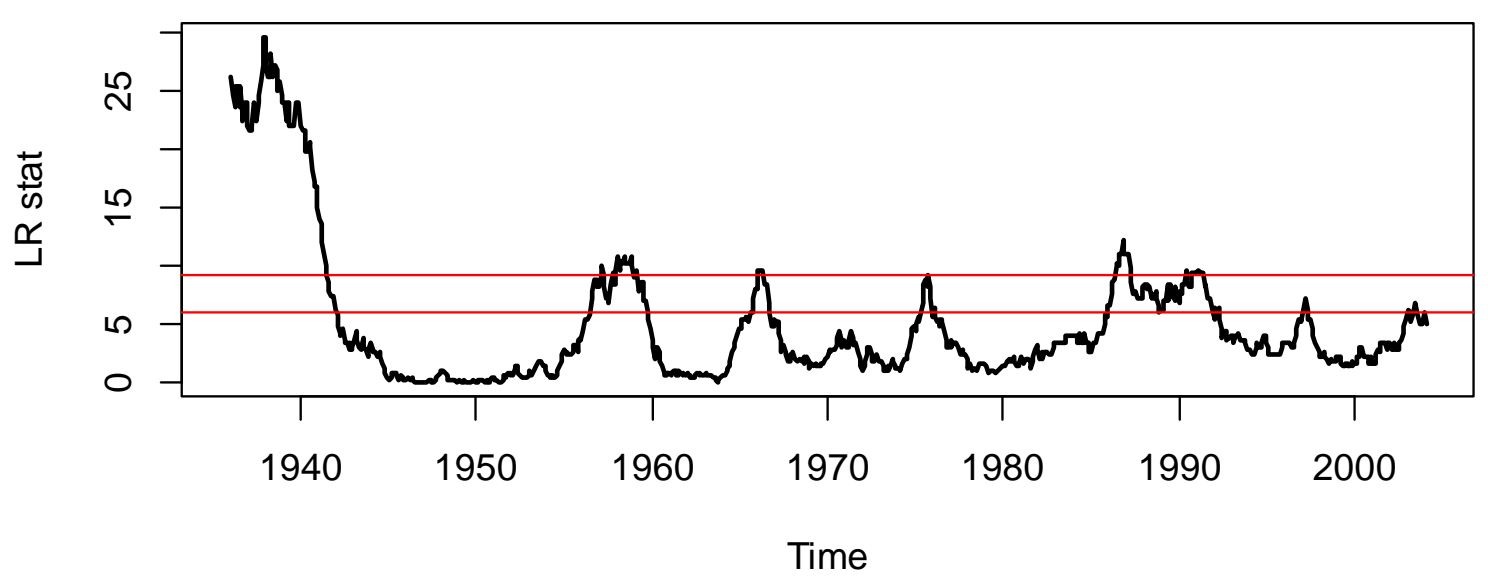

95\% Prediction Interval, $\mathrm{h}=1$

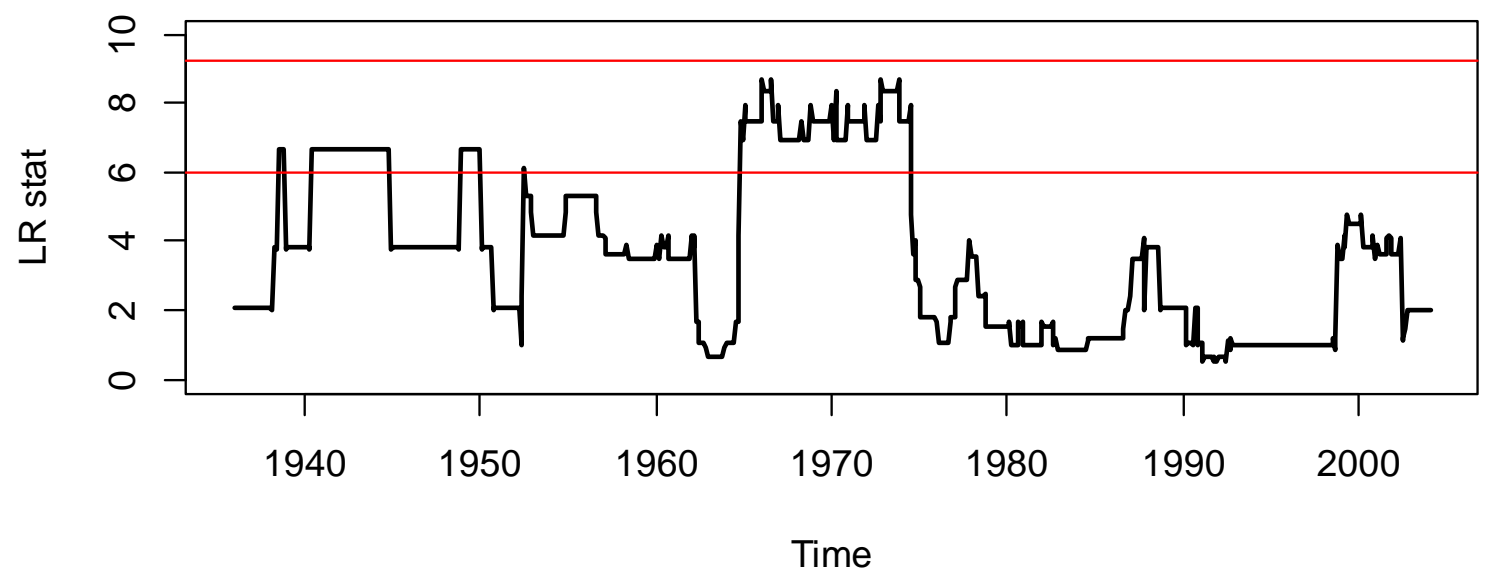

The red horizontal lines correspond to 5.99 and 9.21 , which are $5 \%$ and $1 \%$ critical values from the chi-squared distribution with two degrees of freedom. 
Figure 3. Mean Score of Prediction Intervals
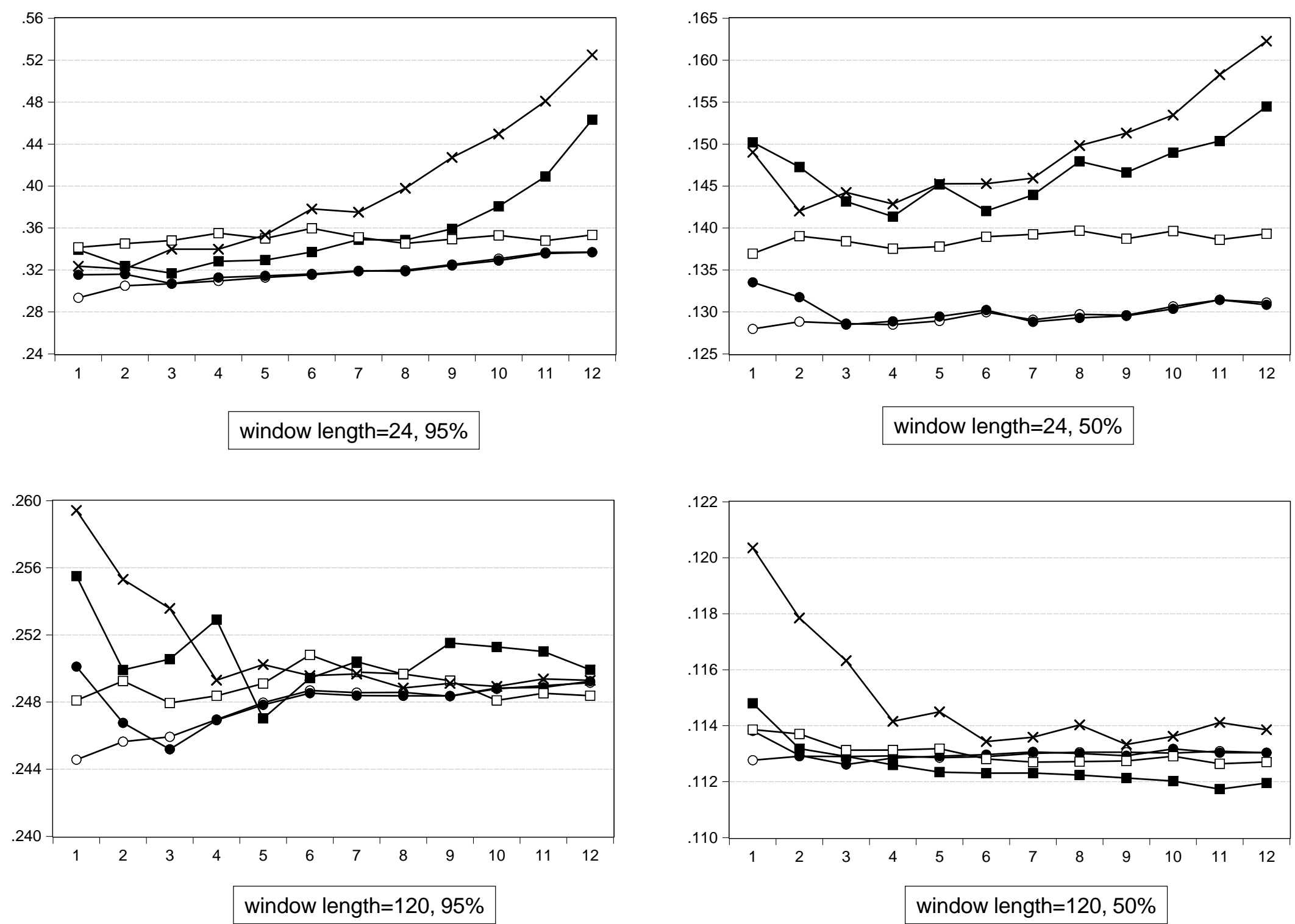

Open Circle: AR(0), Dark Circle: AR(p), Dark Square: AR(p) Bootstrap; Open Square: IARM; Cross: VAR The predictor used in the IARM and VAR is DY (dividend-yiled). 


\section{Figure 4. Mean Interval Scores against Rolling Windows Length}
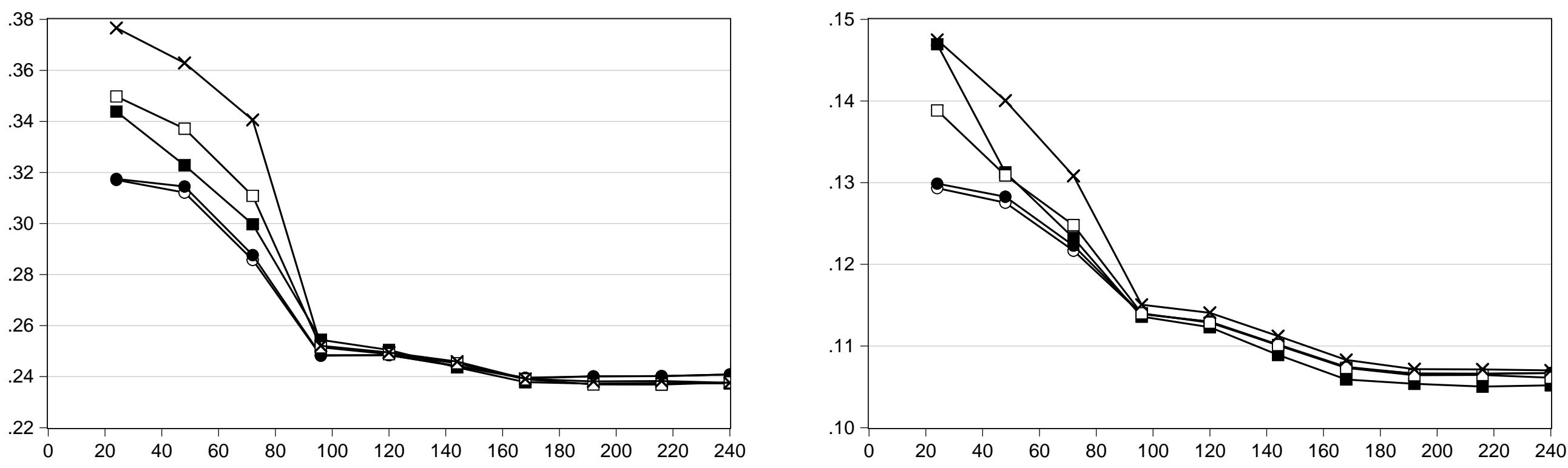

Open Circle: AR(0), Dark Circle: AR(p), Dark Square: AR(p) Bootstrap; Open Square: IARM; Cross: VAR The predictor used in the IARM and VAR is DY (dividend-yiled).

The mean score values plotted are median value over the forecast horizon $1, \ldots, 12$. 
Figure 5. Mean Interval Score of Alternative 95\% Prediction Intervals (Financial Predictors)
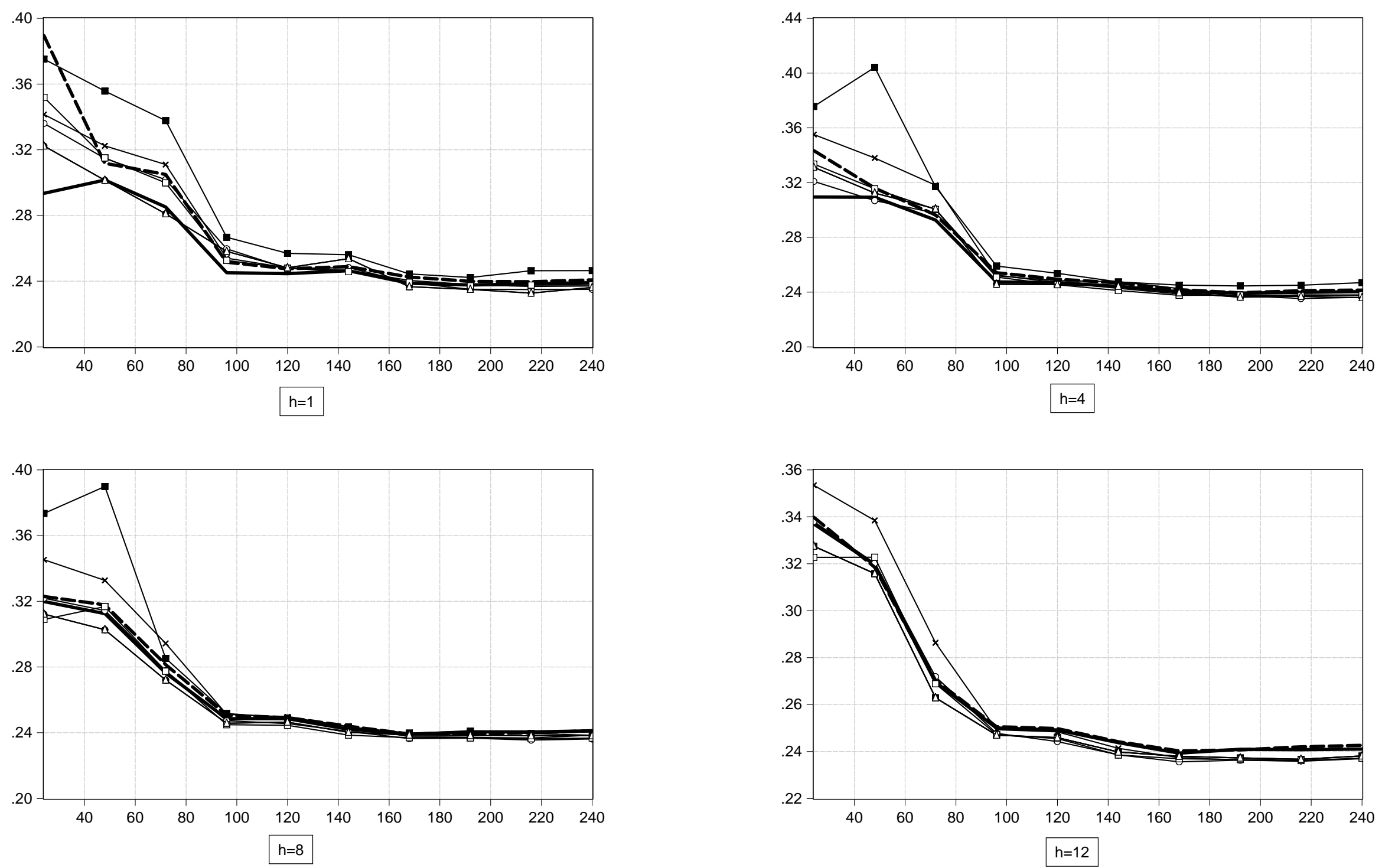

Solid Line: AR(0); dark circile: BM; open circle: DP; cross: DY;

Dark Square: EP; Broken line: inflation; Open Sqaure: PE; Triangle: RF

The IARM is used for all predictors. 
Figure 6. Mean Interval Score of Alternative 95\% Prediction Intervals (Economic Predictors)
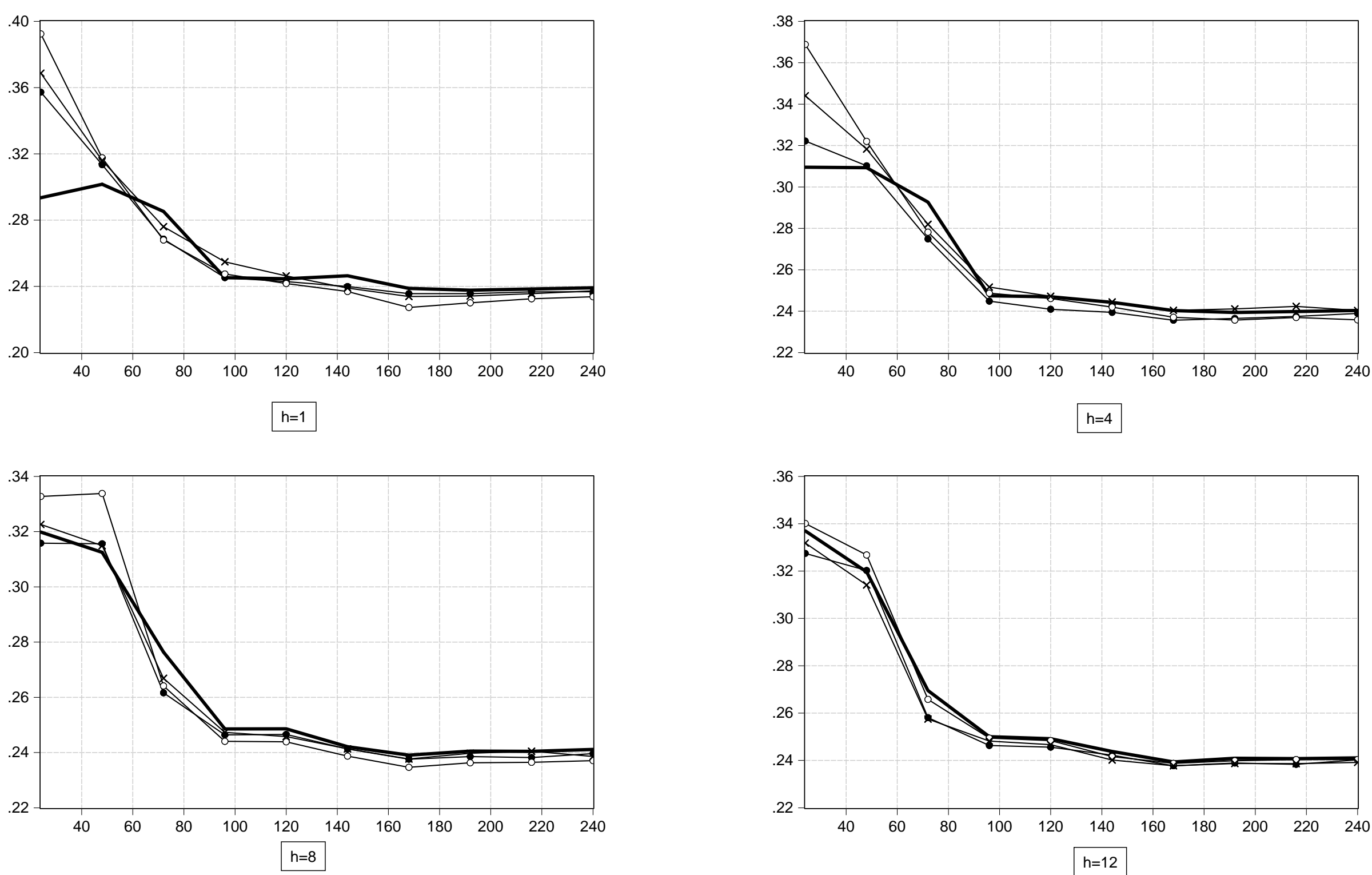

Solid Line: AR(0); dark circile: EPU open circle: GAP; cross: IPH; 
Figure 7. Plot of Interval Scores over time ( $h=1$, rolling window length $=120$ )
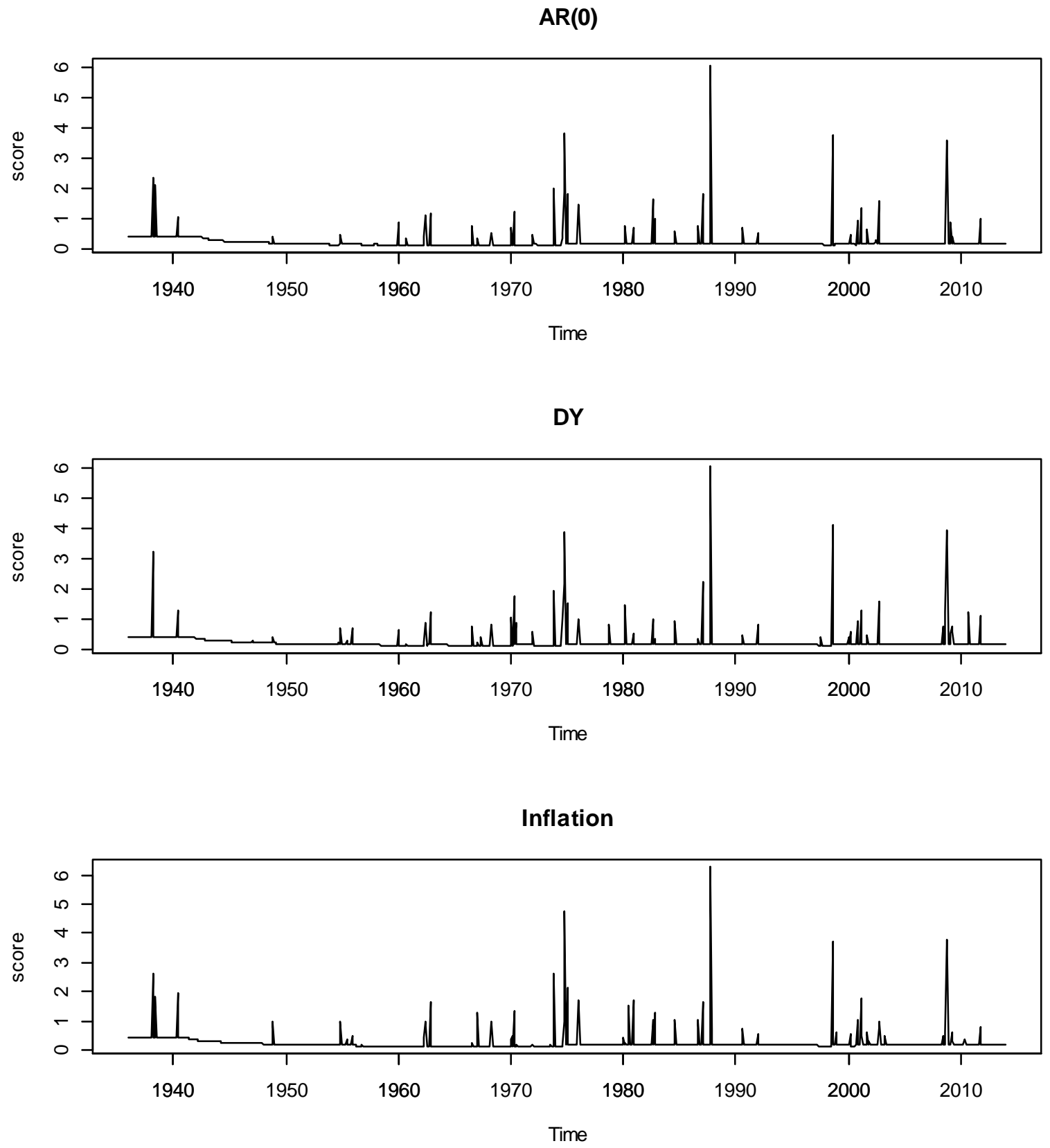

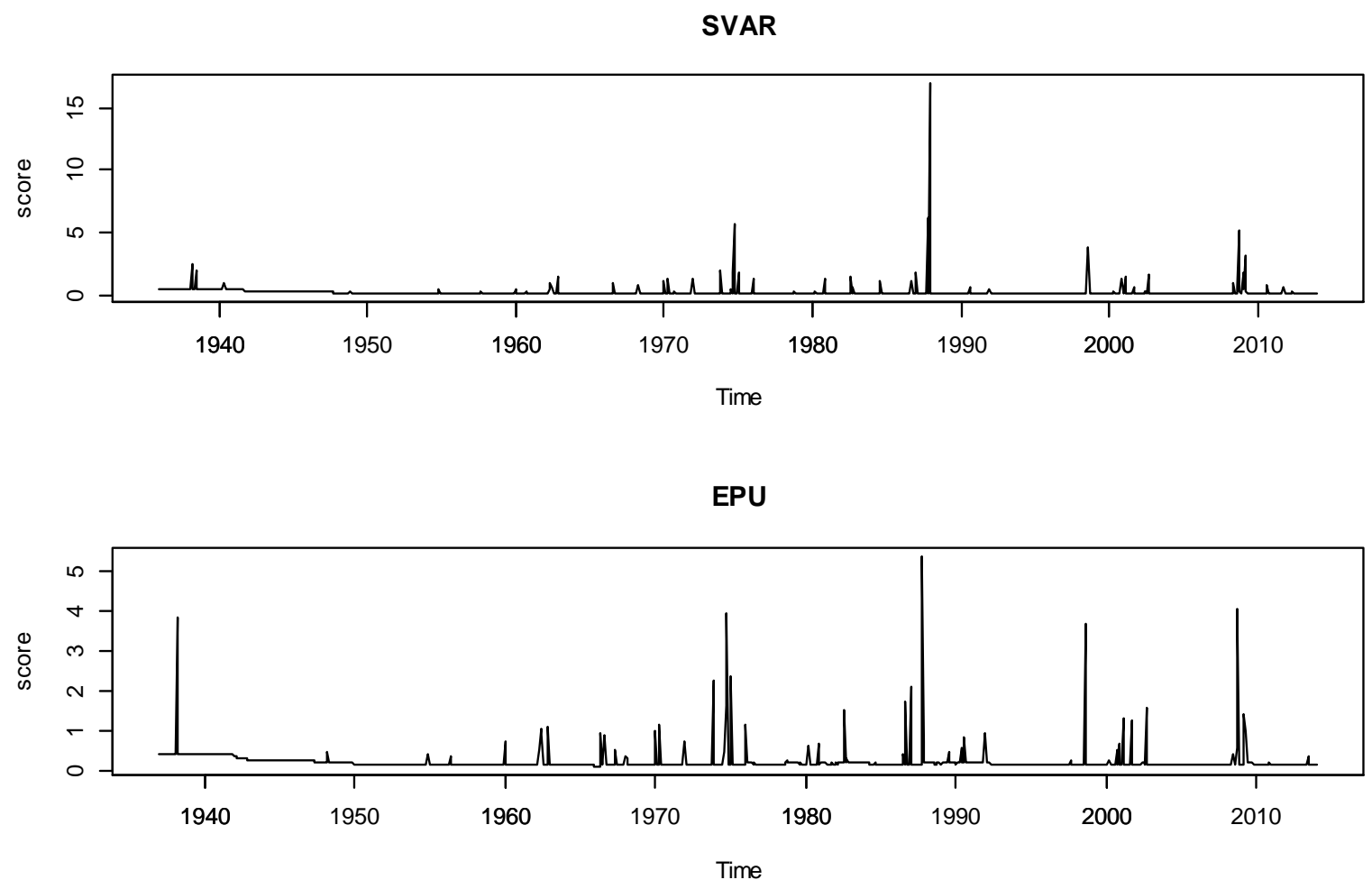

Note: The IARM is used for the model with predictors 

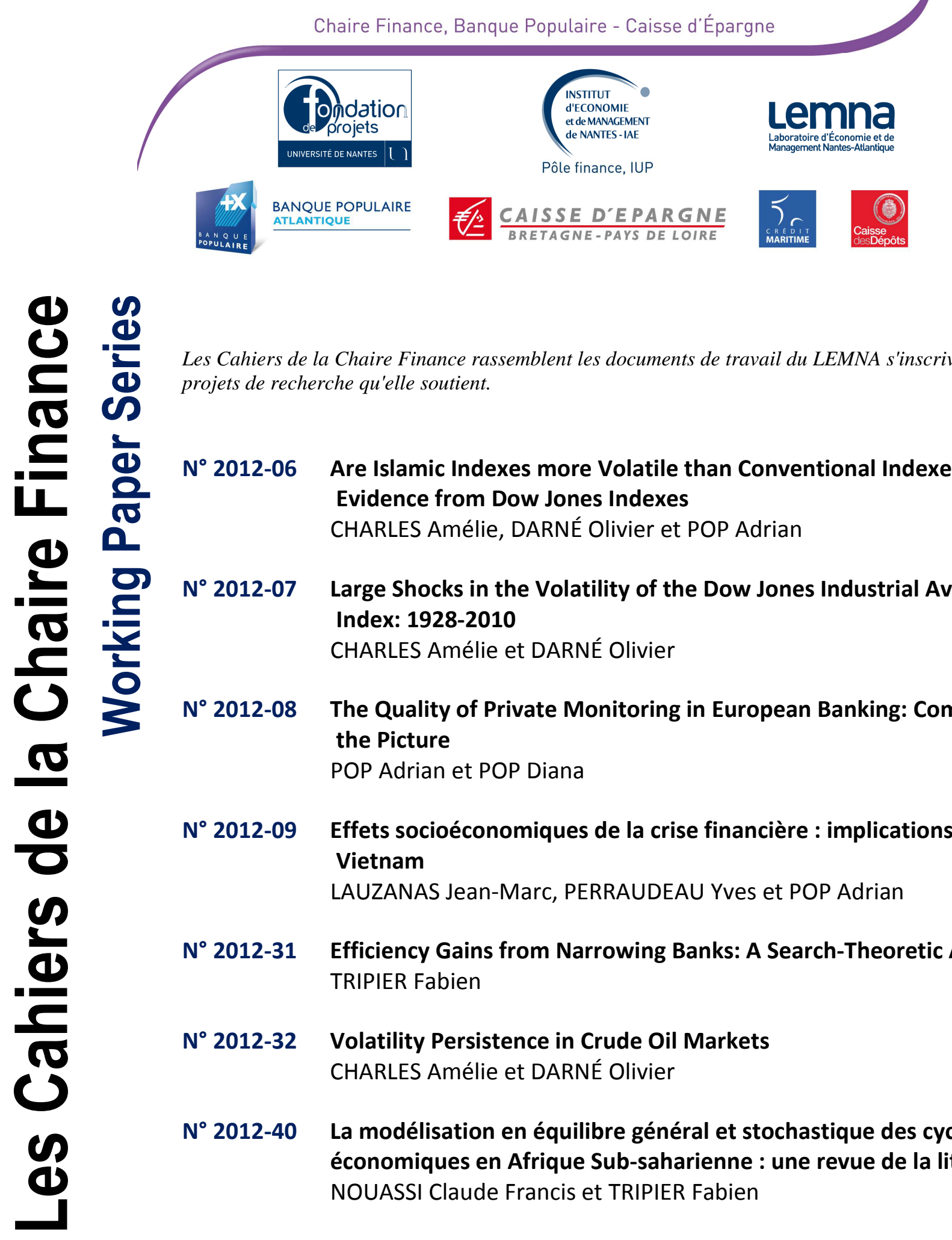

Les Cahiers de la Chaire Finance rassemblent les documents de travail du LEMNA s'inscrivant dans des projets de recherche qu'elle soutient.
$\mathbf{N}^{\circ}$ 2012-06 Are Islamic Indexes more Volatile than Conventional Indexes? Evidence from Dow Jones Indexes
CHARLES Amélie, DARNÉ Olivier et POP Adrian
$\mathbf{N}^{\circ}$ 2012-07 Large Shocks in the Volatility of the Dow Jones Industrial Average Index: 1928-2010
CHARLES Amélie et DARNÉ Olivier
$N^{\circ}$ 2012-08 The Quality of Private Monitoring in European Banking: Completing the Picture
POP Adrian et POP Diana
$\mathbf{N}^{\circ}$ 2012-09 Effets socioéconomiques de la crise financière : implications pour le Vietnam
LAUZANAS Jean-Marc, PERRAUDEAU Yves et POP Adrian
$N^{\circ}$ 2012-31 Efficiency Gains from Narrowing Banks: A Search-Theoretic Approach TRIPIER Fabien
$\mathbf{N}^{\circ}$ 2012-32 Volatility Persistence in Crude Oil Markets CHARLES Amélie et DARNÉ Olivier

$N^{\circ}$ 2012-40 La modélisation en équilibre général et stochastique des cycles économiques en Afrique Sub-saharienne : une revue de la littérature NOUASSI Claude Francis et TRIPIER Fabien

Les opinions exposées dans ce document n'engagent que les auteurs. Ceux-ci assument la responsabilité de toute erreur ou omission.

La Chaire Finance est une initiative de la Banque Populaire Atlantique, la Caisse d'Epargne Bretagne-Pays de Loire, la Caisse des Dépôts, du Crédit Maritime et de l'Université de Nantes, sous l'égide de la Fondation de Projets de I'Université de Nantes.

Site web : http://www.univ-nantes.fr/fondation/chairefinance

\section{Contact}

Chaire Finance, Banque Populaire - Caisse d'Epargne

IEMN-IAE, Chemin de Censive du Tertre - BP 52231

44322 Nantes cedex 3

Tél : +33 (0)2 40141660

Fax : +33(0)2 40141650 

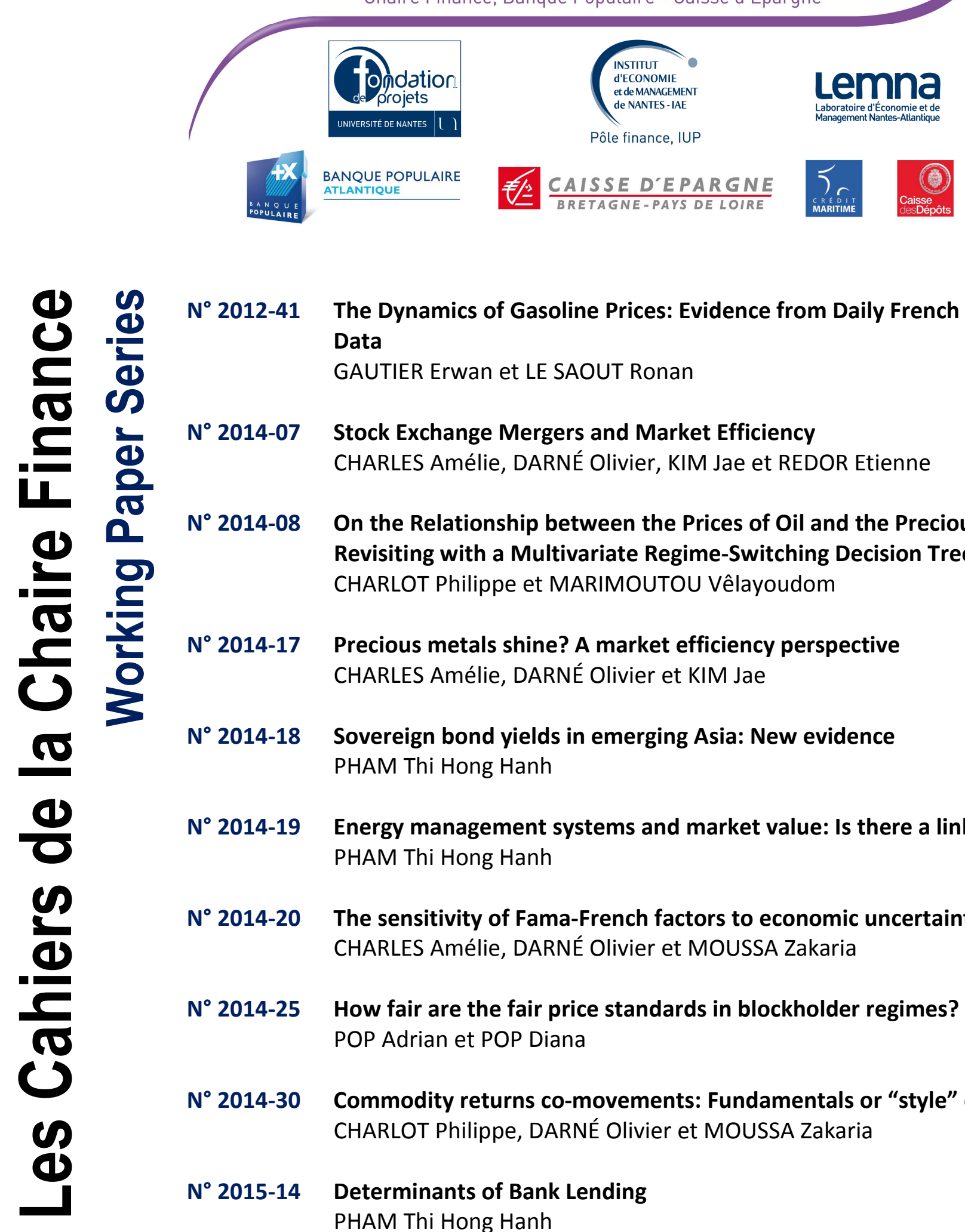

N²012-41 The Dynamics of Gasoline Prices: Evidence from Daily French Micro Data

GAUTIER Erwan et LE SAOUT Ronan

$N^{\circ}$ 2014-07 Stock Exchange Mergers and Market Efficiency

CHARLES Amélie, DARNÉ Olivier, KIM Jae et REDOR Etienne

$N^{\circ}$ 2014-08 On the Relationship between the Prices of Oil and the Precious Metals:

Revisiting with a Multivariate Regime-Switching Decision Tree

CHARLOT Philippe et MARIMOUTOU Vêlayoudom

$N^{\circ}$ 2014-17 Precious metals shine? A market efficiency perspective CHARLES Amélie, DARNÉ Olivier et KIM Jae

$N^{\circ}$ 2014-18 Sovereign bond yields in emerging Asia: New evidence PHAM Thi Hong Hanh

$\mathrm{N}^{\circ}$ 2014-19 Energy management systems and market value: Is there a link? PHAM Thi Hong Hanh

$\mathbf{N}^{\circ}$ 2014-20 The sensitivity of Fama-French factors to economic uncertainty CHARLES Amélie, DARNÉ Olivier et MOUSSA Zakaria

$N^{\circ}$ 2014-25 How fair are the fair price standards in blockholder regimes?

POP Adrian et POP Diana

$N^{\circ}$ 2014-30 Commodity returns co-movements: Fundamentals or "style" effect? CHARLOT Philippe, DARNÉ Olivier et MOUSSA Zakaria

$N^{\circ}$ 2015-14 Determinants of Bank Lending

PHAM Thi Hong Hanh

N²016-04 Stock Return Predictability: Evaluation based on Prediction Intervals CHARLES Amélie, DARNÉ Olivier et KIM Jae 